\title{
Positive Impact of Utilizing More Formative Assessment over Summative Assessment in the EFL/ESL Classroom
}

\author{
José 0. Torres \\ School of Arts and Humanities, Universidad Católica de El Salvador, Santa Ana, El Salvador \\ Email: jose.torres@catolica.edu.sv
}

How to cite this paper: Torres, J. O. (2019). Positive Impact of Utilizing More Formative Assessment over Summative Assessment in the EFL/ESL Classroom. Open Journal of Modern Linguistics, 9, $1-11$.

https://doi.org/10.4236/ojml.2019.91001

Received: November 30, 2018

Accepted: January 28, 2019

Published: January 31, 2019

Copyright $\odot 2019$ by author(s) and Scientific Research Publishing Inc. This work is licensed under the Creative Commons Attribution International License (CC BY 4.0).

http://creativecommons.org/licenses/by/4.0/

\begin{abstract}
Numerous studies about the role of assessment in English as a Foreign Language (EFL) and English as a Second Language (ESL) have been conducted in the last few decades. These studies describe a close connection between language assessment and language teaching. Evidence shows that the way students perceive their results after taking an exam strongly influences their motivation toward using the target language in real communication (Torrance, 2012). In compliance with such studies, this paper provides a general view of language assessment and its implications in the EFL/ESL classroom. The paper aims to provide a general background of language assessment, as well as a contrastive analysis of both summative and formative assessment. The paper approaches the topic from the point of view of both agents involved in the learning process; instructors and students. The findings suggest that students benefit more from formative assessment since it provides them with timely appropriate feedback that helps them shape the way they approach language learning (Huang, 2016). On the other hand, the study highlights that novice teachers usually opt for the traditional summative assessment in order to avoid challenges that formative assessment represents.
\end{abstract}

\section{Keywords}

EFL, ESL, Testing, Evaluation, Summative Assessment, Formative Assessment

\section{Introduction}

Teaching English in the EFL or ESL context is considered by many experts in the field of education as an art and a science (Lupton, 2012). In addition, teaching is much more than just a matter of filling pupils' minds with knowledge related to 
a particular content; instead, it deals with instructors' ability to manage aspects such as lesson planning, students advising, content teaching, observing, evaluating and making decisions (Sardareh, Saad, Othman, \& Me, 2014). Even though some teachers and learners might believe that education is just limited to the act of giving instructions, researchers like Jin (2017) suggest that there is an inseparable connection between the content to teach and the method to use in measuring the degree of achievement of learning goals. This connection can be described as language assessment. Due to the complexity of assessment, language teachers might feel overwhelmed when searching for different types of techniques to use in the classroom; however, it is essential to study its effects on teachers and learners in order to make significant adjustments aimed to better language acquisition. Language assessment is not a new topic in the field of education. In fact, for many years high importance was given to formative assessment in ESL/EFL context; however, the use of such type of assessment as the only mean to determine whether a student passes or fails tends to strongly hinder the individual's development of communication skills (Reyneke, 2016). After carefully studying a series of pros and cons of both forms of language assessment in detail, the evidence demonstrates that the use of more formative assessment in the teaching process impacts positively in students' growth in confidence when using a second or foreign language orally.

\section{The Role of Language Assessment in the Learning Process}

The general concept of language assessment has been subject to multiple changes in the last few decades (Giraldo, 2018). The way assessment is conducted in English as a Foreign Language (EFL) or English as a Second Language (ESL) programs nowadays is somehow different to the way it used to be in the past. Something that has experienced relatively minor changes is the way students see assessment; no matter how much measurement tools have evolved, students keep feeling threatened by the risk of failing a course because of a bad result on a particular exam (Brown, 2010). Therefore, great effort has to be made aimed to change students' misconception of assessment as a torturing tool whose purpose is believed to be a punishment for low learning of the language; in this process, teachers or instructors have the greatest challenge because a big portion of the responsibility lays over their way of teaching.

Before moving forward, it is important to define assessment as a systematic process which takes place throughout the entire teaching/learning act, and which is aimed to judge and make decisions about students' improvement regarding one or multiple skills (García Laborda, Sampson, Hambleton, \& Guzman, 2015). Sometimes the term "language assessment" is confused with the term "language testing." This mistake might drive teachers and students to a predicament on whether assessment in the learning process is good or bad. Therefore, assessment must be seen as the whole process of teaching, observing, testing, judging, making decisions and teaching again; testing is just a small portion of the entire 
assessment process (Özdemir-Yılmazer \& Özkan, 2017).

Assessment goes beyond just giving a test and scoring it; in fact, assessment is intended to provide both students and teachers with a detailed view of the achievement toward the course goals within the teaching/learning process. Ideally, assessment is aimed to benefit students and teachers at the same time; on the one hand, students will benefit from the assessment process by receiving constructive feedback from instructors regarding their advances within the learning process (Huang, 2016). If property given, this feedback might enable students to keep using the learning strategies that had demonstrated to be successful, or to substitute any of the ones that did not have positive impact while facing previous testing experiences. On the other hand, the assessment process also provides instructors with an overview of the degree of appropriateness of their teaching methodology when addressing students' needs; consequentially, they might decide whether to keep using the same techniques or to make any adjustments to them so that the learning process becomes appealing to students. In theory, this is how assessment should proceed in the ESL/EFL context; however, to reach to this point, teachers must have a clear idea of how to conduct appropriate assessment along the whole teaching process, rather than relying on the results of a single testing instrument measuring students' global performance in the classroom (O'Sullivan, 2012).

So far, it has been mentioned that testing is just one step in the whole process of language assessment; hence, some instructors might get confused about it when conducting the appropriate assessment. According to Brown (2010), such processes must take place during the entire teaching process and to illustrate that, the author uses the terms "Formal and Informal Assessment." In theory, when implementing both types of assessment, the teaching and learning process becomes more effective. However, for some teachers, it might represent a challenge, especially when conducting informal assessment. Informal assessment requires all the individuals involved in the learning process to be carefully observed within the entire course or program.

Because of the traditional way of teaching, formal assessment is what all students and teachers might know about. This type of assessment is described as a set of testing instruments that the teacher plans to give at specific times during a course (Özdemir-Y1lmazer \& Özkan, 2017). Informal assessment is presented as a set of techniques that teachers can use to measure students' performance during the whole teaching process (Purpura, 2016). These activities are not necessarily planned to happen at one specific time in the course; they require a certain domain of organizational skills so that teachers conduct the process in an effective way. Examples of informal assessment techniques are spontaneous oral comments instructors give to students when accomplishing a task, coaching students when having difficulties accomplishing a task, putting a sticker on students homework assignment, among others (Brown, 2010).

The assessment should not be a harming process; instead, it must be seen as 
an opportunity for students to better their learning strategies used in a particular course. For teachers, it should be part of a decision-making process aimed to better the quality of instruction within a course. After all, the object of assessment is to benefit all individuals involved in the teaching learning process (Barbosa \& Beserra, 2015). Certainly, the assessment system in an institution might experiences difficulties when trying to change it from one day to another, especially when instructors lack awareness of such a need in the teaching process.

\section{Summative Assessment Overview}

Assessment and teaching are two concepts that have been closely related throughout the last few decades. Many studies have been conducted to analyze the effects of one on the other (Brookhart, 2013). While some authors agree on the fact that assessment is an essential part of the learning process, some others suggest that the overuse of such mechanisms might endanger student's freedom when putting into practice the knowledge acquired in the classroom (Tahereen, 2014). Studies in the field of assessment have demonstrated is that the problem is not really whether to assess students' learning or not; it has to be with the way instructors conduct such process, and how students perceive the results they obtain after taking a testing instrument (Areiza, 2013). The overuse of summative assessment in the classroom should be avoided so that the negative perception of it changes. Then, based on Areiza's (2013) claim, it is necessary to go deeper in the analysis of the way teachers in the field of language teaching are conducting assessment, as well as the effects such processes might be building up in the day-to-day learning context.

One of the most commonly used strategies for measuring students' progress concerning the language learning is by giving midterm and final exams. Such testing tools have been used so repeatedly in the field teaching that all individuals involved in the teaching/learning process know them very well. However, this is just one particular type of assessment that authors like Brown (2010), defines as Summative Assessment. This type of assessment is aimed to obtain reliable data, particularly quantitative data of students' progress in the achievement of a particular course goal (Siegler, Fazio, \& Pyke, 2011). Summative assessment is typically conducted at the end of a course, and its results help teachers determine to what extent students are capable to move ahead to the next level. Its quantitative feature makes this type of assessment a very popular and reliable one in the teaching process. From the perspective of students, this form of measurement does nothing but hinder the learning process because what they receive is a numerical grade used by the teacher to dictate who passes or fails the course. In cases where only summative assessment is used in the classroom, there is no room for a second chance more than just repeating the course. Therefore, relying purely on summative assessment has proven to endanger students' confidence in terms of developing language fluency at a discourse level (Tahereen, 2014). 


\section{Benefits versus Drawbacks of Using Summative Assessment in the ESL/EFL Context}

Even though summative assessment has been criticized, it is one of the most commonly used in the ESL/EFL classroom around the world. According to Brown (2010), this is because of the quantitative feature that summative assessment has gained popularity in the language teaching context. First, summative assessment is intended to be developed during pre-established periods of time. This means that both instructors and students know in advance when any test will take place. From students' perspective, this allows them to prepare for such event; on the other hand, teachers can also foresee possible problematic situation regarding instrument design and make any adjustments to it. Second, a high number of language teachers around the world are nowadays more into conducting summative assessment in the classroom due to its convenience when scoring and reporting results (Purpura, 2016). Such principle in the field of assessment is known as practicality; however, the aforementioned principle of this type of assessment turns to be beneficial only for teachers; from the perspective of students, it only represents quantitative data, which in most of the cases end up preventing learners from developing fluency. Third, summative assessment is considered for experts in the field as one of the most objective measurement systems used in the classroom; due to its quantitative characteristic. It allows teachers to clearly set their point on to what extent students have or have not achieved a particular goal (Purpura, 2016). This last characteristic of summative assessment is not only beneficial for instructors and students; in fact, it also serves as a tangible proof of students' language improvement that parents and program coordinators can see.

Beside the benefit of using summative assessment in the classroom described above, it is important to take a moment and see if it is worth it for teachers to even bother looking for better ways to test students' performance in language learning. As it has been previously described in this article, summative assessment might also hinder students' learning of a second or foreign language, especially when being conducted irresponsibly. Some of the most evident drawbacks of using this type of measurement can be simply recognized by studying its characteristics. First, when adopting this type of assessment as the main way to test students' language proficiency, individuals are tested after the learning process has already ended. Therefore, all participants in the course will know whether they did right or wrong only after the course is over. In other words, the results come too late for any possible adjustments to strategies learners are using to study. Second, a numerical score does not necessarily tell students what they did right or wrong in the process; instead, it tells them whether they passed or failed the course. The idea of giving and receiving feedback are totally left aside when conducting summative assessment in the class. Therefore, students have to discover by themselves what to change for future experiences in their learning process. 


\section{Formative Assessment Overview}

In the last few decades, assessment has been a significant area of study for researchers in the field of education. Such remarkable interest in that particular area is the result of a continuous change in the way teaching is evolving thanks to the emergence of new approaches and technological applications that are used as learning tools. However, the changes in the way the language is learned also produce direct effects on the way such learning is assessed. Authors like Brown (2010) have dedicated time to explore the implications of new teaching strategies on the way learning should be assessed; such studies show strong connections between teaching and evaluation; hence, language assessment is to be determined not only by the content but by the way such content is taught in class (see Figure 1).

As an attempt to match the new ways of teaching, and the best way to assess students' performance in the ESL/EFL classroom, researchers in the field of education have proposed to adopt the application of formative assessment in the class. This type of assessment requires teachers to change the traditional quantitative grading paper systems for a qualitative one. This process includes the effective delivery of feedback by instructors as a response to students' accomplishments on learning tasks (Ketabi \& Ketabi, 2014). In other words, the teacher's job focuses more on modeling the student's way of working through an ongoing guidance process that may or may not take place exclusively inside the classroom. According to Areiza (2013), such ongoing support given to students is what makes formative assessment one of the most effective tools to be used in language teaching. Additionally, it demands from instructors some training on how to provide feedback in a way that students do not feel harmed by the comments they might receive on a particular assignment. Because of that, many novice teachers might opt for the traditional summative assessment, rather than spending time learning about the new methods.

\section{Positive Impact of Using Formative Assessment in the ESL/EFL Classroom}

Despite the misconception some educators have about formative assessment,

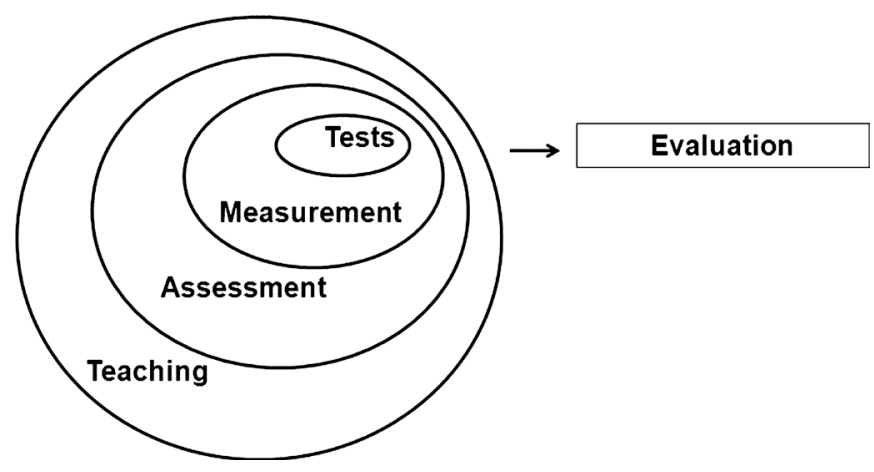

Figure 1. Relationship between test, measurement, assessment, teaching and evaluation. Adapted from Language Assessment Principles and Classroom Practice (p. 6), by H. D. Brown and P. Abeywickrama. Copyright 2010 by Pearson Lognman. 
researchers in the area defend the point that this type of assessment promotes better results in students learning no matter the content (Ketabi \& Ketabi, 2014). Even though some novice teachers might be afraid of changes in the way assessment is carried out, experts like Areiza (2013) agree that moving from the traditional to formative assessment does not require great changes; in fact, many of the testing instruments used in one evaluation system can be adapted to make them more formative featured. For example, the use of alternative instruments such as journals, task-based projects, self-evaluation, and peer-evaluation can be both formative and summative. The key to the success of these instruments in the formative context comes from the quality of feedback students receive from instructors; in addition, the follow-up revision activity students go through after being notified of any possible mistakes on activity tasks pushes them to develop self-awareness of language mistakes. Such feedback and room for revision should be what make the difference between a simple numerical score and a well-detailed one-on-one conference between instructor and student.

Formative assessment positively impacts the teachers' performance in the classroom as well as on the development of language skills by learners. From the perspective of the teachers, it serves as a reflection state within the course so that weaknesses can be identified and remediated. For instance, when the majority of pupils in the room struggle to master a content, it does not necessarily mean lack of interest from them. In fact, it might happen to be that the techniques used by the teacher might not be addressing students' learning needs. Considering that formative assessment takes place during the whole course, adjustments in the development of the lessons can be made so that the content and the methodology aligns with what students need. In addition, by conducting formative assessment, teachers increase the number of sources for collecting data aimed to determine the degree of achievement of a learning goal. When opting for formative assessment type, the evaluation is made based on multiple insights such as, students' presentation of homework assignments, attendance to class, participation in class, quality of the language used in the classroom during discussions, efforts made outside the classroom in terms of using the target language, etc.

From the perspective of learners, formative assessment enhances the development of language skills due to its qualitative feature. Based on the literature reviewed, it can be said that, by receiving timely appropriate feedback, learners are given the chance to prevent the fossilization of language issues they might have early in the learning process. In addition, during one-to-one feedback sessions, students are also given the chance to ask for clarification questions regarding observations made by the teacher. Furthermore, learners are given the opportunity to demonstrate the degree of achievement of the learning goals through different channels, and therefore, to be promoted to an upper proficiency level. In the case of formative assessment, the quantitative grade is only a part of the data used to evaluate the learner's acquisition of the target language. Finally, formative assessment has proved to be less harming than any other types 
of it; formative assessment promotes rapport in the class, which is the good relationship between students and teachers. The fact of receiving oral feedback from the teacher makes students notice recognition in the classroom; moreover, they receive personalized instruction on issues they should consider for future experiences using the target language.

\section{Classroom Implications}

So far, formative assessment and some of its most significant advantages in ESL/EFL context have been described, as well as the role that feedback plays when opting for this type of assessment. Giving feedback, however, is much more than just telling students what they did wrong so that they can fix it. Before giving feedback, instructors have to carefully analyze students' piece of work, and share their comments based on specific points to be addressed (Mansourizadeh \& Izwan, 2014). For example, if the teacher is giving feedback on the spelling of a written essay, all observations and suggestions should be related to spelling and not grammar or composition. Undoubtedly, aspects like the one mentioned before cause that some teachers opt for relying on the typical final written exam of the course. However, it has been proven not only that students work better after receiving feedback, but also that they highly value teachers' suggestions on any assignment (Best, Jones-Katz, Smolarek, Stolzenburg, \& Williamson, 2014). In fact, students in the EFL classroom complain that sometimes, they do not know what a numerical grade really means after receiving an exam back, they usually look for the teacher to clarify their doubts regarding a bad grade (Mansourizadeh \& Izwan, 2014).

Receiving feedback can be as painful and meaninglessness as a bad numerical score on a particular task. For some pupils, attending a feedback session with the instructor can be a really frustrating experience, especially when the instructor focuses only on negative feedback (Hedgcock \& Ferris, 2014). This kind of feedback is also known as "destructive feedback", and it prevents students' learning. In fact, the aim of feedback should not be harming learners, but rather to guide pupils in the way learning tasks can be done improved so that they build their knowledge on a particular content. This fact drives people involved in the teaching/learning process to be aware of the importance of knowing how to give and how to receive feedback. Both parties need training so that those involved in such process obtain only the benefits of a well-conducted one-on-one conference session.

\section{Conclusion}

For many years, educators have discussed the important relationship between language teaching and language assessment in the EFL/ESL classroom. Numerous studies suggest that instruction by its own does not guarantee learning; instead; it is just one piece conforming a very complex system. Elements such as testing, evaluating and assessing play a very remarkable role in such process. 
Consequentially, great attention should be paid to all elements and not just to one. Language assessment is one of the most important steps in the language teaching process because it provides teachers and students with apposite feedback on the direction such process follows. Certainly, the theory suggests multiple ways to deal with giving and receiving feedback. On one hand, feedback can be provided as a numerical grade aimed to determine whether students approve or fail a course; or it can be given as a corrective one-on-one conference in the form of comments.

Knowing that language assessment and language teaching are processes that are strongly connected, it is essential to deeply study not only the way each system works but also the way one might directly affect the other. Considering that teaching involves teachers and students, it is important to see the practicality of assessment from the perspectives of both individuals. Therefore, if the process benefits one individual but harms the other, it turns into an unreliable source of information. The aim of this paper is not to dismiss the importance of implementing summative assessment in the ESL/EFL classrooms; instead, it is intended to alert teachers about the importance of conducting a deep analysis of the techniques being used to measure students' performance regarding the learning of the language. It also instructs on how to improve such process so that it turns to a skill development process rather than just a simple "pass" or "fail" determiner instrument.

Certainly, changes might sometimes represent great challenges for educators and students, especially when information is not enough to understand the reasons for such changes; however, in the field of education, it is essential to keep updating not only the way the content is taught in the ESL/EFL classroom but also how the measurement of the goal achieved is conducted. Assessment can be based on quantitative parameters; however, it has been demonstrated that this system is beneficial only for instructors because it represents a practical way of grading and reporting students' results. Conversely, instructors might opt for adopting a formative assessment system that allows them to promote students' learning throughout continuous input of constructive feedback during and after the development of a course. Indeed, this last system involves much more effort from instructors. Students' learning of a second or foreign language is worth such effort.

According to this study, both summative and formative assessment are necessary in the teaching/learning process; however, evidence shows that students benefit the most from comments of instructors since they serve as a guide for students to follow the path that best suits their learning process.

\section{Conflicts of Interest}

The author declares no conflicts of interest regarding the publication of this paper.

\section{References}

Areiza, H. (2013). The Role of Systematic Formative Assessment on Students' Views of 
Their Learning. Australian Journal of Education, 15, 1657-1790.

Barbosa, M., \& Beserra, L. S. (2015). Formative Assessment in the Foreign Language Classroom. BELT: Brazilian English Language Teaching Journal, 6, 100-109. https://doi.org/10.15448/2178-3640.2015.1.20200

Best, K., Jones-Katz, L., Smolarek, B., Stolzenburg, M., \& Williamson, D. (2014). Listening to Our Students: An Exploratory Practice Study of ESL Writing Students' Views of Feedback. TESOL Journal, 2, n/a-n/a.

Brookhart, S. M. (2013). The Use of Teacher Judgment for Summative Assessment in the USA. Assessment in Education: Principles, Policy \& Practice, 20, 69-90. https://doi.org/10.1080/0969594X.2012.703170

Brown, H. D. (2010). Language Assessment, Principles and Classroom Practices (2nd ed.). New York: Pearson Lognman.

García Laborda, J., Sampson, D. G., Hambleton, R. K., \& Guzman, E. (2015). Guest Editorial: Technology Supported Assessment in Formal and Informal Learning. Journal of Educational Technology \& Society, 18, 1-2.

http://login.ezproxy.lib.umn.edu/login?url=http://search.ebscohost.com/login.aspx?dir ect=true \&AuthType $=\mathrm{ip}, \mathrm{uid} \& \mathrm{db}=\mathrm{aph} \& \mathrm{AN}=102557855 \&$ site $=$ ehost-live

Giraldo, F. (2018). Language Assessment Literacy: Implications for Language Teachers. PROFILE: Issues in Teachers' Professional Development, 20, 179-195. https://doi.org/10.15446/profile.v20n1.62089

Hedgcock, J. S., \& Ferris, D. R. (2014). Teaching L2 Composition Purpose, Process, and Practice (3rd ed.). New York: Routledge.

Huang, S.-C. (2016). Understanding Learners' Self-Assessment and Self-Feedback on Their Foreign Language Speaking Performance. Assessment \& Evaluation in Higher Education, 41, 803-820.

https://doi-org.ezproxy.waterfield.murraystate.edu/10.1080/02602938.2015.1042426 https://doi.org/10.1080/02602938.2015.1042426

Jin, Y. (2017). Construct and Content in Context: Implications for Language Learning, Teaching and Assessment in China. Language Testing in Asia, 7, 1-18. https://doi.org/10.1186/s40468-017-0032-5

Ketabi, S., \& Ketabi, S. (2014). Classroom and Formative Assessment in Second/Foreign Language Teaching and Learning. Theory and Practice in Language Studies, 4, 435-440. https://doi.org/10.4304/tpls.4.2.435-440

Lupton, M. (2012). Reclaiming the Art of Teaching. Teaching in Higher Education, 18, $1-11$.

Mansourizadeh, K., \& Izwan, A. K. (2014). The Effects of Oral and Written Meta-Linguistic Feedback on ESL Students Writing. The Southeast Asian Journal of English Language Studies, 20, 117-1263. https://doi.org/10.17576/3L-2014-2002-10

O'Sullivan, B. (2012). Assessment Issues in Languages for Specific Purposes. Modern Language Journal, 96, 71-88. https://doi.org/10.1111/j.1540-4781.2012.01298.x

Özdemir-Yılmazer, M., \& Özkan, Y. (2017). Classroom Assessment Practices of English Language Instructors. Journal of Language \& Linguistics Studies, 13, 324-345.

http://waterfield.murraystate.edu/login?url=http://search.ebscohost.com/login.aspx?dir $\underline{\text { ect }=\text { true } \& \mathrm{db}=\text { eue } \& A N=126127410 \& \text { site }=\text { ehost-live\&scope }=\text { site }}$

Purpura, J. E. (2016). Second and Foreign Language Assessment. The Modern Language Journal, 100, 190-208. https://doi.org/10.1111/modl.12308

Reyneke, E. (2016). School-Based Assessment in English Language Teaching: Weighing the Cow Will Not Fatten It. Per Linguam: A Journal of Language Learning, 32, 1-14. 
https://doi.org/10.5785/32-2-624

Sardareh, S. A., Saad, M. R. M., Othman, A. J., \& Me, R. C. (2014). ESL Teachers' Questioning Technique in an Assessment for Learning Context: Promising or Problematic? International Education Studies, 7, 161-174. https://doi.org/10.5539/ies.v7n9p161

Siegler, R. S., Fazio, L. K., \& Pyke, A. (2011). There Is Nothing So Practical as a Good Theory. Ian Australian Journal of Education, 171-197. https://doi.org/10.1016/B978-0-12-387691-1.00006-5

Tahereen, T. (2014). Testing Based Language Teaching in Bangladesh: Does It Promote or Impede Learning? TESOL International Journal, 9, 148-178.

Torrance, H. (2012). Formative Assessment at the Crossroads: Conformative, Deformative and Transformative Assessment. Oxford Review of Education, 38, 323-342. https://doi.org/10.1080/03054985.2012.689693 